\title{
Synapsin Function in GABA-ergic Interneurons Is Required for Short-Term Olfactory Habituation
}

\author{
Madhumala K. Sadanandappa, ${ }^{1}$ Beatriz Blanco Redondo, ${ }^{2}$ Birgit Michels, ${ }^{3}$ Veronica Rodrigues, ${ }^{\dagger}$ Bertram Gerber, ${ }^{3}$ \\ K. VijayRaghavan, ${ }^{1}$ Erich Buchner, ${ }^{2}$ and Mani Ramaswami ${ }^{1,4}$ \\ ${ }^{1}$ National Centre for Biological Sciences, Bangalore 560065, India, ${ }^{2}$ Institute for Clinical Neurobiology, University of Würzburg, 97078 Würzburg, Germany, \\ ${ }^{3}$ Department of Genetics for Learning and Memory, Leibniz Institute for Neurobiology, 39118 Magdeburg, Germany, ${ }^{4}$ School of Genetics and Microbiology, \\ School of Natural Sciences, Smurfit Institute of Genetics and Trinity College Institute of Neuroscience, Trinity College Dublin, Dublin-2, Ireland
}

In Drosophila, short-term (STH) and long-term habituation (LTH) of olfactory avoidance behavior are believed to arise from the selective potentiation of GABAergic synapses between multiglomerular local circuit interneurons (LNs) and projection neurons in the antennal lobe. However, the underlying mechanisms remain poorly understood. Here, we show that synapsin (syn) function is necessary for STH and that $s y n^{97}$-null mutant defects in STH can be rescued by syn ${ }^{+}$cDNA expression solely in the LN1 subset of GABAergic local interneurons. As synapsin is a synaptic vesicle-clustering phosphoprotein, these observations identify a presynaptic mechanism for STH as well as the inhibitory interneurons in which this mechanism is deployed. Serine residues 6 and/or 533, potential kinase target sites of synapsin, are necessary for synapsin function suggesting that synapsin phosphorylation is essential for STH. Consistently, biochemical analyses using a phospho-synapsin-specific antiserum show that synapsin is a target of $\mathrm{Ca}^{2+}$ calmodulin-dependent kinase II (CaMKII) phosphorylation in vivo. Additional behavioral and genetic observations demonstrate that CaMKII function is necessary in LNs for STH. Together, these data support a model in which CaMKII-mediated synapsin phosphorylation in LNs induces synaptic vesicle mobilization and thereby presynaptic facilitation of GABA release that underlies olfactory STH. Finally, the striking observation that LTH occurs normally in $\operatorname{syn}^{97}$ mutants indicates that signaling pathways for STH and LTH diverge upstream of synapsin function in GABAergic interneurons.

\section{Introduction}

Mechanisms for synaptic plasticity have been intensively analyzed in reduced preparations, e.g., in hippocampal or corticalslice preparations and in neuromuscular synapses, e.g., of Aplysia, crayfish, frog, lamprey, and Drosophila. In contrast, synaptic mechanisms underlying specific forms of behavioral learning are less well understood in vivo, in terms of the signaling pathways engaged by experience as well as the cell types in which these mechanisms operate. The analysis of such in vivo mecha-

Received July 25, 2013; revised Sept. 6, 2013; accepted Sept. 11, 2013.

Author contributions: M.K.S., B.B.R., V.R., K.V., E.B., and M.R. designed research; M.K.S. and B.B.R. performed research; B.M., B.G., and E.B. contributed unpublished reagents/analytic tools; M.K.S., K.V., E.B., and M.R. analyzed data; M.K.S., K.V., E.B., and M.R. wrote the paper.

This work was supported by grants from Science Foundation Ireland to M.R. and Department of Biotechnology, India, to K.V. and to the late Veronica Rodrigues, whose guidance and inspiration drove this work. M.K.S. was supported by INSPIRE fellowship from Department of Science and Technology, India, as well as the Biocon India scholarship, provided by Biocon, Bangalore, and Trinity College Dublin, Ireland. This work was also funded by German Science Foundation grants DFG-SFB554, DFG-SFB581, and DFG-GRK1156 to E.B. and DFG-SFB779 to B.G. and B.M. We acknowledge Kei lto, Gero Miesenböck, and Sam Kunes for fly stocks. We thank our laboratory members for useful discussions; Adrian Dervan, Isabell Twick, John Lee, Jens Hillebrand, Sudeshna Das, and Indulekha Sudhakaran for many helpful suggestions; and the NCBS Central Imaging and Flowcytometry Facility. The monoclonal antibodies $3 \mathrm{C} 11$ and nc82 developed by A. Hofbauer and E. Buchner were obtained from the Developmental Studies Hybridoma Bank developed under the auspices of the National Institute of Child Health and Human Development and maintained by The University of lowa Department of Biology.

${ }^{\dagger}$ Deceased, November 10, 2010.

Correspondence should be addressed to Mani Ramaswami, Trinity College Institute of Neuroscience, Lloyd Building, Trinity College Dublin, Dublin-2 Ireland. E-mail: mani.ramaswami@tcd.ie.

DOI:10.1523/JNEUROSCI.3142-13.2013

Copyright $\odot 2013$ the authors $\quad 0270-6474 / 13 / 3316576-10 \$ 15.00 / 0$ nisms of plasticity requires an accessible neural circuit, whose properties are measurably altered by experience.

The olfactory response in Drosophila is initiated by the activation of odorant receptors expressed in the olfactory sensory neurons (OSNs), which project into the antennal lobe (AL) and form synapses with glomerulus-specific projection neurons (PNs) that wire to both, the mushroom bodies $(\mathrm{MB})$ and the lateral protocerebrum. OSNs and PNs also activate multiglomerular excitatory and inhibitory local interneurons (LNs), which mediate lateral and intraglomerular inhibition in the AL (Vosshall and Stocker, 2007; Chou et al., 2010). We recently provided strong evidence for a model in which Drosophila olfactory habituation, i.e., reduced olfactory avoidance caused by previous exposure to an odorant arises through potentiation of inhibitory transmission between GABAergic LNs and PNs of the AL (Das et al., 2011). In this study, we analyze the molecular basis of this potentiation and propose a mechanism that could lead to increased presynaptic GABA release after odorant exposure.

Synapsins are a conserved family of synaptic vesicle-associated proteins. They are predominantly associated with the reserve pool of synaptic vesicles and their phosphorylation by kinases such as calcium-dependent protein kinases (CaMKs), protein kinase A (PKA), and MAPK/Erk, result in the mobilization of these vesicles and thereby induces presynaptic facilitation (Südhof et al., 1989; Greengard et al., 1993; Li et al., 1995; Pieribone et al., 1995; Kao et al., 1999; Kuromi and Kidokoro, 2000; Fiumara et al., 2004; Hilfiker et al., 2005; Akbergenova and Bykhovskaia, 
2007; Cesca et al., 2010). While synapsin may play key roles in behavioral plasticity in mammals (Cui et al., 2008), its functions in learning and memory remain mysterious in part because mammals have three synapsins (I, II, and III) encoded by three different genes (Südhof et al., 1989; Hosaka and Südhof, 1998a, b).

Recent studies of the single synapsin gene in Drosophila (Klagges et al., 1996; Diegelmann et al., 2013) show that it is required for adult anesthesia-sensitive memory of odor-shock association (Knapek et al., 2010). Larval associative memory requires synapsin with intact phosphorylation target sites (Ser6 and Ser533) likely operating in a subset of MB neurons (Michels et al., 2005, 2011).

Here, we ask whether, where, and how synapsin functions in olfactory habituation. Our observations indicate that short-term habituation $(\mathrm{STH})$ requires synapsin function as well as its CaMKII-dependent phosphorylation in the LN1 subset of inhibitory interneurons in the AL. These point to presynaptic facilitation of GABA release as being a crucial mechanism for STH. The observation that long-term habituation (LTH) forms normally in $s y n^{97}$ mutants indicates that this form of long-term memory can be encoded without transition through a short-term memory stage.

\section{Materials and Methods}

Fly reagents. All flies were raised at $25^{\circ} \mathrm{C}$ on standard cornmeal agar medium; Canton S (CS) flies were used as wild-type controls for all the behavioral experiments, unless otherwise specified. The flies used for experiments were obtained from different sources: LN1-Gal4 (II) from Kei Ito (University of Tokyo), GAD1-Gal4 (II) from Gero Miesenböck (Oxford University, Oxford, UK), UAS-CaMKII ${ }^{R N A i}$ (II) from Sam Kunes (Harvard University, Boston, MA), elav-Gal4 (X, C155) and UASCaMKII-ala (II) from Bloomington (stock numbers 458 and 29666, respectively), and UAS-syn ${ }^{R N A i}$ (II) from VDRC (46480 GD). syn ${ }^{97}$-null mutant (III), UAS-syn-cDNA,syn ${ }^{97}$ (edited wild-type synapsin rescue construct, in the following denoted as UAS-syn ${ }^{+}, \operatorname{syn}^{97}$ ) (III), UAS-syn ala-ala, $\operatorname{syn}^{97}$ (III), GH146-Gal4; syn ${ }^{97}$ (II, III), and mb247-Gal4,syn ${ }^{97}$ (III) lines have been described previously (Löhr et al., 2002; Godenschwege et al., 2004; Michels et al., 2011). For this study the $\operatorname{syn}^{97}$ flies had been backcrossed to wild-type CS over at least 12 generations to avoid the influence of genetic background effects (Godenschwege et al., 2004; Michels et al., 2005). For rescue experiments all Gal4 drivers were crossed into the $\operatorname{syn}^{97}$-null mutant background.

Protocol for inducing habituation. For measuring the olfactory responses of flies, we used the Y-maze apparatus as previously described (Das et al., 2011). Protocols for inducing and measuring habituation were also as described earlier (Das et al., 2011; McCann et al., 2011; Sudhakaran et al., 2012).

For STH. Four-day-old flies were starved overnight ( $\sim 25-30$ flies per vial with a moist filter paper). These flies were subjected to a pretest to measure the naive response to either $10^{-3}$ dilution of ethyl butyrate (EB) or to $5 \% \mathrm{CO}_{2}$. For $\mathrm{EB}$ exposure, flies were transferred to a $125 \mathrm{ml}$ glass bottle in which a $1.5 \mathrm{ml}$ Eppendorf tube containing 5\% EB (diluted in paraffin oil) with perforated lid was suspended. For inducing STH to $\mathrm{CO}_{2}$, the vials containing the flies were covered with cheesecloth and placed inside a $\mathrm{CO}_{2}(15 \%)$ incubator. After $30 \mathrm{~min}$ of $\mathrm{EB}$ or $\mathrm{CO}_{2}$ exposure, the flies' responses were tested to $10^{-3} \mathrm{~EB}$ or to $5 \% \mathrm{CO}_{2}$, respectively, using the Y-maze.

For LTH. Flies ( 0 - to 12-h-old; 100-130) were transferred to a plastic bottle containing fresh cornmeal media. A $1.5 \mathrm{ml}$ Eppendorf tube containing 20\% EB (diluted in paraffin oil) covered with perforated plastic wrap was suspended inside the bottle containing the flies, whereas for $\mathrm{CO}_{2}$ exposure, the bottles were covered with cheesecloth and placed inside a $\mathrm{CO}_{2}(5 \%)$ incubator for $4 \mathrm{~d}$. Control flies (mock) were exposed to $1 \mathrm{ml}$ of paraffin oil or to air for $4 \mathrm{~d}$ at $25^{\circ} \mathrm{C}$. After an overnight starvation, control and exposed flies were tested for the behavioral response using the Y-maze.
Response index (RI) was calculated for naive/mock- and odorexposed flies, based on the fraction of flies in the odorant compartment minus the fraction of flies in the air compartment divided by the total number of files that participated in the experiment. The RI values were presented as the percentage response of the naive response of the flies (except Fig. 1C). Statistical significance was determined by Student's $t$ test and ANOVA including Bonferroni correction for multiple comparisons $\left({ }^{\star} p<0.05 /\right.$ Bonferroni correction factor $(\mathrm{BCF}),{ }^{* *} p<0.01 / \mathrm{BCF}$, ${ }^{* * *} p<0.001 / \mathrm{BCF}$, respectively). BCF $=2$ for Figs. $1 B, 2 E, F, 4 B, C, D, 5 A$; $\mathrm{BCF}=3$ for Fig. $5 B ; \mathrm{BCF}=5$ for Fig. $2 B ; \mathrm{BCF}=6$ for Fig. $3 D$ ) using OriginPro data analyzing and graphing software.

Conditional expression experiments using the heat-sensitive Gal4 suppressor, tub-Gal80 ${ }^{t s}$. For synapsin rescue experiments, flies were grown and maintained at $18^{\circ} \mathrm{C}$ until $3 \mathrm{~d}$ after eclosion. Flies were shifted to $29^{\circ} \mathrm{C}$ $1 \mathrm{~d}$ before testing. For RNAi-mediated knock down and for UASCaMKII-ala overexpression experiments, flies were raised at $18^{\circ} \mathrm{C}$ and after eclosion 0 - to 12 -h-old flies were shifted to $29^{\circ} \mathrm{C}$ and aged for $4 \mathrm{~d}$. Control flies for knock down and rescue experiments were maintained at $18^{\circ} \mathrm{C}$.

For LTH experiments (LN1-Gal4; tub-Gal80 ${ }^{\text {ts }}>$ UAS-CaMKII-ala), 0to 12 - h-old flies were exposed to odorant and controls to paraffin oil, for $4 \mathrm{~d}$ at $29^{\circ} \mathrm{C}$. and genotype controls at $18^{\circ} \mathrm{C}$.

Flies were starved in their respective temperature regimes for $6 \mathrm{~h}$ and $1 \mathrm{~h}$ at room temperature, before subjecting them to the Y-maze behavioral test.

Immunohistochemistry. Adult fly brain dissections were performed in $1 \times$ PBS and fixed in freshly prepared 4\% EM grade paraformaldehyde (prepared in $1 \times$ PBS) for $30 \mathrm{~min}$ at room temperature. Fixative was removed and the samples were washed with $0.3 \%$ PTX ( $0.3 \%$ of Triton X in $1 \times$ PBS) for $1 \mathrm{~h}(3$ washes $\times 20 \mathrm{~min})$ at room temperature. Blocking was performed at room temperature for $30 \mathrm{~min}$ using $5 \%$ normal goat serum prepared in $0.3 \%$ PTX and incubated at $4^{\circ} \mathrm{C}$ for $48 \mathrm{~h}$ for labeling with primary antibodies. After incubation, brains were washed with $0.3 \%$ PTX ( 3 washes $\times 20 \mathrm{~min}$ ) and incubated overnight at $4^{\circ} \mathrm{C}$ with secondary antibodies. The labeled samples were washed with $0.3 \%$ PTX ( 3 washes $\times$ $20 \mathrm{~min}$ ) and mounted using Vectashield (H-1000; Vector Laboratories). The primary antibodies, mouse $\alpha$-synapsin $(\mathrm{mAb} 3 \mathrm{C} 11,1: 10)$ and mouse $\alpha$-Bruchpilot (mAb nc82, 1:10), were acquired from Developmental Studies Hybridoma Bank in Iowa. The secondary antibodies were Alexa 488- and Alexa 568-coupled goat $\alpha$-mouse from Invitrogen used in 1:400 dilutions. All the images (optical sections $0.5 \mu \mathrm{m}$ intervals with a picture size of $512 \times 512$ pixels) were acquired using a confocal microscope (FV1000 Laser Scanning Confocal Microscope; Olympus). Data processing and pseudocoloring were performed using Adobe Photoshop CS3 (Adobe Systems).

Glomerular measurements. To quantify the change in glomerular volume before and after LTH, acquired confocal images were first converted into tiff files and then imported into Amira 5.2.0 software (Visage Imaging). Using the nc82 staining, 3D reconstruction of glomeruli was generated to calculate their volumes (Das et al., 2011). Genotypes and experimental conditions were coded such that the experimenter was blind with respect to these parameters. Only female flies were used for dissections and single data point represents mean of at least 16-20 measured glomerular volumes. Student's $t$ test with Bonferroni correction was applied to the raw data points to calculate the statistical significance between different experimental conditions.

SDS-PAGE and Western blotting protocol. The procedure for SDSPAGE and Western blotting has been described in detail previously (Halder et al., 2011) and was adapted with minor modifications. Briefly, after protein transfer, the membranes were blocked overnight in $5 \%(\mathrm{w} / \mathrm{v})$ nonfat dry milk (Carl Roth) prepared in $1 \times$ TBST (100 mM Tris, $150 \mathrm{~mm}$ $\mathrm{NaCl}$, and $0.5 \% \mathrm{v} / \mathrm{v}$ Tween 20 ) at $4^{\circ} \mathrm{C}$. Next day, the blots were incubated for $2 \mathrm{~h}$ at room temperature with primary antibodies at suitable dilutions in $1 \times$ TBST. Thereafter the blots were incubated for $1 \mathrm{~h}$ with secondary antibodies: goat $\alpha$-mouse horseradish peroxidase (HRP) and goat $\alpha$-rabbit HRP at dilution of 1:3000 (both from Invitrogen). Blots were developed with an ECL kit (GE Healthcare) and visualized using AGFA $\mathrm{CP}-1000 \mathrm{x}$-ray film. The following antibodies were used: mouse monoclonal $\alpha$-synapsin (mAb 3C11; 1:200) and mouse monoclonal $\alpha$-SAP47 
(mAb nc46; 1:200; Hofbauer et al., 2009). The custom-made rabbit antiserum Psyn-S6 was generated against the S6-phosphorylated nonedited $\mathrm{N}$-terminal synapsin peptide $\mathrm{NH}_{2}-$ MKRRFS ${ }^{\mathrm{P}}$ SGDLSSC-CONH${ }_{2}$, affinity purified and absorbed against the nonphosphorylated peptide (Eurogentec; www.eurogentec.com), and used at 1:200 dilutions.

\section{Results}

\section{Synapsin is necessary for STH}

Synapsin-null mutants $\left(s y n^{97}\right)$ are viable and healthy (Godenschwege et al., 2004) and therefore can be used for behavioral studies of olfactory response measured using a Y-maze apparatus. In wild-type Drosophila $30 \mathrm{~min}$ of odorant exposure $\left(5 \% \mathrm{~EB}\right.$ or $\left.15 \% \mathrm{CO}_{2}\right)$ results in the odorant-specific decrement of olfactory avoidance that recovers within $1 \mathrm{~h}$ (Das et al., 2011; Fig. 1B). This phenomenon of $\mathrm{STH}$ is lost in $\mathrm{syn}^{97}$ mutants, indicating that synapsin is necessary for the establishment of this form of nonassociative memory (Fig. $1 A, B$, Table 1 ). To rule out possible confounding effects from altered olfactory responses in $s y n^{97}$ flies, we tested the olfactory response of mutant flies at various concentrations of EB. The odor avoidance behavior of $s y n^{97}$ flies tested for different dilutions of $\mathrm{EB}\left(10^{-4}, 10^{-3.5}\right.$, and $10^{-3}$ dilutions) are very similar to those of wild-type flies (Fig. 1C). Thus, the STH phenotype of $\operatorname{syn}^{97}$ flies is not due to an inability to detect and respond to EB and presumably to other odors.

\section{Synapsin function is required in AL GABAergic local interneurons}

Synapsin is a neuronal protein localized in the majority of presynaptic terminals, where it functions to enable presynaptic facilitation (Godenschwege et al., 2004; Akbergenova and Bykhovskaia, 2007). Given the requirement of synapsin for STH, we next performed experiments to identify the specific neuronal type in the olfactory circuit where synapsin function is sufficient and where it is necessary. This, in turn would identify the specific presynaptic terminals in which short-term facilitation operates in olfactory habituation. We therefore first asked if expression of wild-type synapsin in specific neuronal subsets was sufficient to rescue STH defects in Drosophila syn ${ }^{97}$ mutants and then asked further if RNAi-mediated knock down of synapsin in these neuronal subsets blocked STH in otherwise wild-type flies.

We used the Drosophila Gal4 system combined with UAS$s y n^{+}$in $s y n^{97}$ background (Michels et al., 2011) and UAS$s y n^{R N A i}$ transgenes in wild-type background for these experiments. Expression of a wild-type synapsin construct in either the LN1 class of GABAergic local interneurons or in all GABA-positive neurons marked by GAD1-Gal4 rescues the syn ${ }^{97}$ defect for STH (Fig. 2A1,A2,B, Table 1). Thus, LN1-Gal4>UAS$\operatorname{syn}^{+}, \operatorname{syn}^{97} /$ syn $^{97}$ and GAD1-Gal4> UAS-syn ${ }^{+}$, syn $^{97} /$ syn $^{97}$ flies showed STH indistinguishable from the wild-type.

In contrast, the expression of synapsin in the vast majority of AL PNs (GH146-Gal4>UAS-syn ${ }^{+}$, syn $^{97} /$ syn $^{97}$; Fig. 2A3) or MB neurons using mb247-Gal4 (mb247-Gal4> UAS-syn ${ }^{+}$, syn $^{97}$ / $s y n^{97}$; Fig. 2A4), has no effect on $s y n^{97}$ mutant phenotype (Fig. $2 B$,
Table 1; Das et al., 2011, see their supplementary data for the various Gal4 controls). This is significant because: (1) activation of GH146-positive PNs is necessary and sufficient for inducing habituation to EB (Sudhakaran et al., 2012) and (2) synapsin likely functions in $\mathrm{mb247}$-expressing MB neurons for larval associative learning (Michels et al., 2011).

To rule out the possibility that synapsin plays a role on the normal development of LN1 interneurons and to further test the sufficiency and necessity of synapsin expression in adult LN1 neurons, we used the $t u b-G a l 80^{t s}$ system in which a temperaturesensitive form of Gal80, an inhibitor of Gal4, is ubiquitously expressed for adult-specific $s y n^{+}$rescue in $s y n^{97}$ background or adult-specific $s y n^{R N A i}$ knock down in the wild-type background (Fig. 2C,D). Cell-specific, conditional rescue experiments suggest that synapsin function in adult LN1 neurons (in LN1-Gal4> tub-Gal80 ${ }^{\text {ts }}$; UAS-syn ${ }^{+}$, syn $^{97} /$ syn $^{97}$ flies) is sufficient to allow induction of STH to $\mathrm{EB}$ and $\mathrm{CO}_{2}$ (Fig. 2C, Table 1). In addition, adult-specific removal of synapsin in LN1 neurons using RNAi (in LN1-Gal4; tub-Gal80 ${ }^{t s}>U A S-s y n^{R N A i}$ flies) results in the block of STH showing that synapsin is necessary in these neurons (Fig. 2D, Table 1).

Thus, synapsin function in LN1 neurons is sufficient and necessary for STH. Together with prior work (Das et al., 2011) these data indicate a key role for synapsin-mediated facilitation of transmitter release in the potentiation of LN-PN synapses during STH.

\section{Synapsin phosphorylation sites are essential for STH}

The classic model for synapsin function postulates that its phosphorylation by cAMP- and/or $\mathrm{Ca}^{2+}$-calmodulin-dependent kinase I/II (PKA and CaMKs) results in its detachment from reserve pool of synaptic vesicles (Llinás et al., 1985; Südhof et al., 1989; Hosaka et al., 1999; Kuromi and Kidokoro, 2000; Fiumara 
Table 1. Showing the raw RI values* for naive and odor-exposed flies with number of sets (in parentheses) and statistical results ( $t$ values, degrees of freedom, and $p$ values) for all the experimental genotypes

\begin{tabular}{|c|c|c|c|c|c|c|c|}
\hline \multirow[b]{2}{*}{ Figure } & \multirow[b]{2}{*}{ Genotype (STH experiments) } & \multicolumn{3}{|c|}{ Negative RI for EB STH } & \multicolumn{3}{|c|}{ Negative Rl for $\mathrm{CO}_{2} \mathrm{STH}^{* *}$} \\
\hline & & Naive & Exposed & $\begin{array}{l}t_{(\mathrm{df})}=t \text { value, } \\
p=p \text { value }\end{array}$ & Naive & Exposed & $\begin{array}{l}t_{(\mathrm{df})}=t \text { value, } \\
p=p \text { value }\end{array}$ \\
\hline \multirow[t]{2}{*}{ 1B } & CS & $0.68 \pm 0.009(9)$ & $0.30 \pm 0.02(9)$ & $t_{(16)}=-13.33, p<0.001$ & $0.50 \pm 0.01(8)$ & $0.24 \pm 0.02(8)$ & $t_{(14)}=-11.70, p<0.001$ \\
\hline & syn $n^{97}$ & $0.71 \pm 0.01(10)$ & $0.71 \pm 0.02(10)$ & $t_{(18)}=0.21, p=0.83$ & $0.52 \pm 0.01(10)$ & $0.52 \pm 0.02(10)$ & $t_{(18)}=0.05, p=0.96$ \\
\hline \multirow[t]{5}{*}{$2 B$} & UAS-syn ${ }^{+}$, syn $^{97} /$ syn $^{97}$ & $0.64 \pm 0.02(9)$ & $0.68 \pm 0.02(9)$ & $t_{(16)}=1.53, p=0.15$ & $0.66 \pm 0.02(9)$ & $0.69 \pm 0.03(9)$ & $t_{(16)}=0.86, p=0.40$ \\
\hline & LN1-Gal4/+;UAS-syn ${ }^{+}$, syn $^{97} /$ syn $^{97}$ & $0.72 \pm 0.02(11)$ & $0.33 \pm 0.01(10)$ & $t_{(19)}=-18.56, p<0.001$ & $0.65 \pm 0.02(11)$ & $0.32 \pm 0.01(11)$ & $t_{(20)}=-12.32, p<0.001$ \\
\hline & GAD1-Gal4/+;UAS-syn ${ }^{+}$, syn $^{97} /$ syn $^{97}$ & $0.65 \pm 0.02(10)$ & $0.28 \pm 0.02(10)$ & $t_{(18)}=-11.01, p<0.001$ & $0.55 \pm 0.01(9)$ & $0.24 \pm 0.02(9)$ & $t_{(16)}=-14.59, p<0.001$ \\
\hline & GH146-Gal4/+;UAS-syn ${ }^{+}$, syn $^{97} /$ syn $^{97}$ & $0.78 \pm 0.03(11)$ & $0.74 \pm 0.02(11)$ & $t_{(20)}=-1.01, p=0.32$ & - & - & - \\
\hline & mb247-Gal4,syn ${ }^{97} /$ UAS-syn $^{+}$, syn ${ }^{97}$ & $0.62 \pm 0.02(10)$ & $0.65 \pm 0.02(10)$ & $t_{(18)}=1.36, p=0.19$ & $0.66 \pm 0.02(10)$ & $0.70 \pm 0.02(10)$ & $t_{(18)}=1.38, p=0.18$ \\
\hline \multirow[t]{2}{*}{$2 C$} & 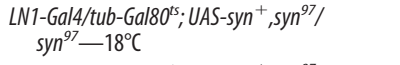 & $0.73 \pm 0.02(10)$ & $0.67 \pm 0.02(10)$ & $t_{(18)}=-1.77, p=0.09$ & $0.56 \pm 0.03(9)$ & $0.62 \pm 0.02(9)$ & $t_{(16)}=1.64, p=0.12$ \\
\hline & 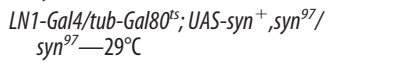 & $0.72 \pm 0.02(10)$ & $0.37 \pm 0.05(10)$ & $t_{(18)}=-6.30, p<0.001$ & $0.51 \pm 0.03(9)$ & $0.36 \pm 0.02(9)$ & $t_{(16)}=-4.50, p<0.001$ \\
\hline \multirow[t]{2}{*}{ 2D } & 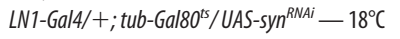 & $0.69 \pm 0.02(10)$ & $0.30 \pm 0.01(10)$ & $t_{(18)}=-14.18, p<0.001$ & $0.51 \pm 0.007(3)$ & $0.20 \pm 0.03(3)$ & $t_{(4)}=-5.26, p<0.001$ \\
\hline & LN1-Gal4/+; tub-Gal $80^{t 5} /$ UAS-syn ${ }^{R N A i}-29^{\circ} \mathrm{C}$ & $0.74 \pm 0.05(10)$ & $0.70 \pm 0.03(10)$ & $t_{(18)}=-0.57, p=0.58$ & $0.56 \pm 0.03(3)$ & $0.54 \pm 0.02(3)$ & $t_{(4)}=-0.19, p=0.86$ \\
\hline \multirow[t]{6}{*}{ 3D } & CS & $0.61 \pm 0.03(8)$ & $0.29 \pm 0.03(8)$ & $t_{(14)}=-7.11, p<0.001$ & $0.53 \pm 0.03(5)$ & $0.21 \pm 0.04(5)$ & $t_{(8)}=-6.33, p<0.001$ \\
\hline & UAS-syn $n^{\text {ala-ala }}$, syn $^{97} /$ syn $^{97}$ & $0.68 \pm 0.04(10)$ & $0.64 \pm 0.03(10)$ & $t_{(18)}=-0.76, p=0.46$ & $0.65 \pm 0.02(10)$ & $0.67 \pm 0.01(10)$ & $t_{(18)}=1.31, p=0.21$ \\
\hline & LN1-Gal4/+;UAS-synn ala-ala syn $^{97} /$ syn $^{97}$ & $0.65 \pm 0.02(9)$ & $0.64 \pm 0.01(9)$ & $t_{(16)}=-0.49, p=0.63$ & $0.69 \pm 0.02(10)$ & $0.69 \pm 0.02(10)$ & $t_{(18)}=4.44, p=1.00$ \\
\hline & GAD1-Gal4/+;UAS-syn ala-ala ,syn $^{97} /$ syn $^{97}$ & $0.64 \pm 0.01(11)$ & $0.62 \pm 0.02(11)$ & $t_{(20)}=-0.63, p=0.53$ & $0.65 \pm 0.01(10)$ & $0.66 \pm 0.02(10)$ & $t_{(18)}=0.31, p=0.76$ \\
\hline & LN1-Gal4/+;UAS-syn ${ }^{\text {ala-ala }}$, syn $^{97} /+$ & $0.61 \pm 0.02(10)$ & $0.28 \pm 0.02(10)$ & $t_{(18)}=-12.91, p<0.001$ & $0.49 \pm 0.02(9)$ & $0.18 \pm 0.03(9)$ & $t_{(16)}=-8.36, p<0.001$ \\
\hline & GAD1-Gal4/+;UAS-syn ala-ala, syn $^{97} /+$ & $0.63 \pm 0.02(10)$ & $0.22 \pm 0.03(10)$ & $t_{(18)}=-10.45, p<0.001$ & $0.60 \pm 0.02(10)$ & $0.28 \pm 0.02(10)$ & $t_{(18)}=-10.16, p<0.001$ \\
\hline \multirow[t]{2}{*}{$4 \mathrm{~B}$} & $\begin{array}{l}\text { LN1-Gal4/UAS-CaMKII-ala; tub-Gal80 } \\
\quad+-18^{\circ} \mathrm{C}\end{array}$ & $0.61 \pm 0.02(11)$ & $0.34 \pm 0.02(11)$ & $t_{(20)}=-8.98, p<0.001$ & $0.58 \pm 0.02(7)$ & $0.30 \pm 0.01(7)$ & $t_{(12)}=-11.37, p<0.001$ \\
\hline & $\begin{array}{l}\text { LN1-Gal4/UAS-CaMKII-ala; tub-Gals0 } \\
\quad+-29^{\circ} \mathrm{C}\end{array}$ & $0.69 \pm 0.03(11)$ & $0.69 \pm 0.03(11)$ & $t_{(20)}=0.10, p=0.92$ & $0.55 \pm 0.03(9)$ & $0.58 \pm 0.03(9)$ & $t_{(16)}=0.89, p=0.39$ \\
\hline \multirow[t]{2}{*}{$4 C$} & 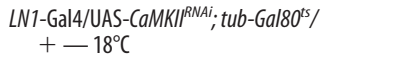 & $0.65 \pm 0.01(9)$ & $0.27 \pm 0.03(9)$ & $t_{(16)}=-10.76, p<0.001$ & - & - & - \\
\hline & 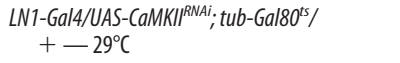 & $0.62 \pm 0.01(9)$ & $0.63 \pm 0.02(9)$ & $t_{(16)}=0.43, p=0.67$ & - & - & - \\
\hline \multirow{4}{*}{$\begin{array}{l}\text { Gal4 Controls } \\
\text { (for 2B) }\end{array}$} & LN1-Gal4; syn $^{97}$ & $0.70 \pm 0.02(10)$ & $0.64 \pm 0.03(10)$ & $t_{(18)}=-1.70, p=0.11$ & $0.61 \pm 0.02(10)$ & $0.64 \pm 0.02(10)$ & $t_{(18)}=1.15, p=0.27$ \\
\hline & GAD1-Gal4; syn ${ }^{97}$ & $0.67 \pm 0.03(9)$ & $0.69 \pm 0.01(9)$ & $t_{(16)}=0.23, p=0.82$ & $0.52 \pm 0.03(10)$ & $0.60 \pm 0.03(10)$ & $t_{(18)}=1.97, p=0.07$ \\
\hline & GH146-Gal4; syn ${ }^{97}$ & $0.7 \pm 0.02(9)$ & $0.68 \pm 0.01(9)$ & $t_{(16)}=-0.78, p=0.45$ & - & - & - \\
\hline & mb247-Gal4,syn ${ }^{97}$ & $0.66 \pm 0.03(9)$ & $0.64 \pm 0.02(9)$ & $t_{(16)}=-0.63, p=0.54$ & $0.53 \pm 0.02(10)$ & $0.58 \pm 0.03(10)$ & $t_{(18)}=1.15, p=0.27$ \\
\hline
\end{tabular}

*Values are $\pm \mathrm{SEM} .{ }^{*}$ For $\mathrm{CO}_{2}$ habituation experiments, histograms are not provided in the figures only raw RI values of before and after habituation responses are documented in the table along with number of sets and statistical results.

et al., 2004; Cesca et al., 2010; Giachello et al., 2012; Diegelmann et al., 2013). This allows additional synaptic vesicles to be made available for neurotransmitter release. Consistent with this, at the Drosophila larval motor synapse, tetanic stimulation results in the transient increase of neurotransmitter release by mobilization of vesicles from the reserved pool to the active pool through a synapsin-dependent mechanism (Kuromi and Kidokoro, 2000, 2002; Akbergenova and Bykhovskaia, 2007). Thus synapsin acts as a regulator for neurotransmitter release.

Drosophila synapsin is phosphorylated at least at seven sites identified by mass spectrometry and verified by phosphatase treatment (Nuwal et al., 2011). Two additional sites, motif 1 in the conserved " $A$ " domain and motif 2 near the " $E$ " domain, conform to both the PKA (RRxS) and the CaMKII (RxxS) consensus motifs (Fig. 3A; Klagges et al., 1996; Diegelmann et al., 2006). We tested whether these two potential phosphorylation sites are essential for synapsin function in STH, using a transgenic synapsin construct mutated at these predicted kinasephosphorylation sites.

In the Drosophila phospho-mutated synapsin construct (UAS-syn ${ }^{\text {ala-ala }}$ ), the serine 6 (S6) and 533 (S533) at the two predicted consensus motifs ( $\mathrm{RRxS})$ for kinases are replaced by alanines (Michels et al., 2011). This mutant construct is efficiently expressed but not phosphorylated at motif 1 in vivo, as judged using antibodies against synapsin $(3 \mathrm{C} 11)$ and a phospho-specific antiserum that recognizes the $\mathrm{S6}$-phosphorylated form of synap$\sin (\alpha$-Psyn-S6). As expected, $\alpha$-Psyn-S6 signal in elav-Gal4> $U A S-s y n^{\text {ala-ala }}, s y n^{97} /$ syn $^{97}$ head extracts are indistinguishable from that of $s y n^{97}$ flies although synapsin is efficiently expressed as revealed by the $\alpha$-synapsin antibody (Fig. 3B, for synapsin signal compare lane 3 and 4 ).

This phosphorylation of synapsin appears to be necessary for its role in LN1 and GAD1-expressing neurons during STH. That is, while expression of a wild-type synapsin transgene construct in these cells rescues the $s y n^{97}$ defect in STH, expression of the UASsyn $n^{\text {ala-ala }}$ construct in either LN1 neurons (LN1-Gal4> UAS$s y n^{\text {ala-ala }}, \operatorname{syn}^{97} / \mathrm{syn}^{97}$ ) or in GABAergic neurons (GAD1-Gal4> $\left.U A S-s y n^{\text {ala-ala }}, s y n^{97} / s^{2} y n^{97}\right)$ has no effect on the $s y n^{97}$ defects in $\mathrm{STH}$ to $\mathrm{EB}$ or $\mathrm{CO}_{2}$ (Fig. 3C,D, Table 1), although mutant and wild-type transgenes are expressed at comparable levels (compare Figs. 2A1,A2, 3C1,C2).

We excluded the possibility of a dominant-negative effect of the transgene by confirming that expression of the UAS-syn ala-ala construct in LN1 and GAD1-positive neurons did not affect normal STH in animals heterozygous for $s y n^{97}$. Thus, LN1-Gal4> $U A S-s^{\text {ala-ala }}$, syn $^{97} /+$ and GAD1-Gal4>UAS-syn ${ }^{\text {ala-ala }}$, syn $^{97} /+$ flies showed STH similar to that of wild-type flies (Fig. 3D, first, fifth, and sixth pair of bars; note that a dominant-negative effect of the drivers is excluded both by these data, and by the successful rescue when driving the wild-type construct; Fig. 2B).

Thus, the observation that synapsin phosphorylation sites are required for STH indicates that synapsin phosphorylation is necessary in GABAergic LN1 neurons for its function in STH and supports a model in which kinase-dependent synapsin phosphorylation mobilizes reserve synaptic vesicles in LN1 neurons and thereby enhances GABA release from the LN1 presynapse. This increase in neurotransmitter release from LN1 neurons 


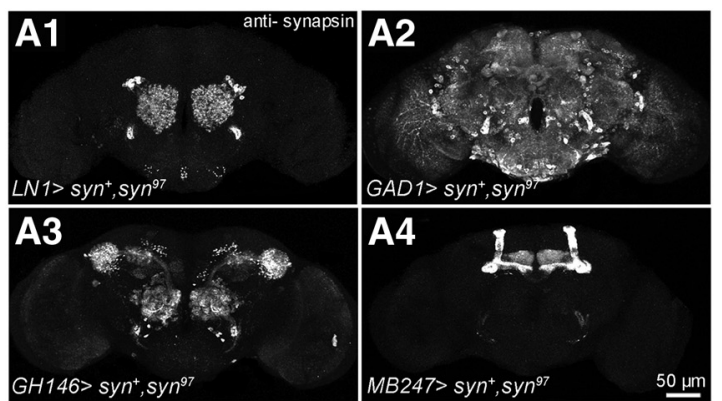

B

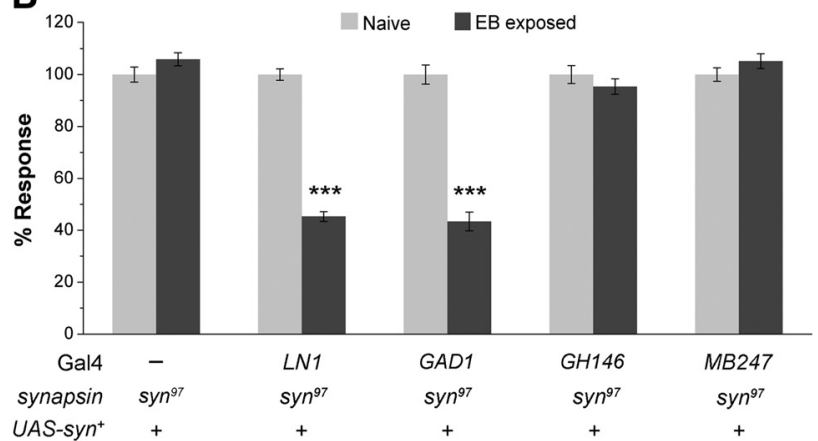

C
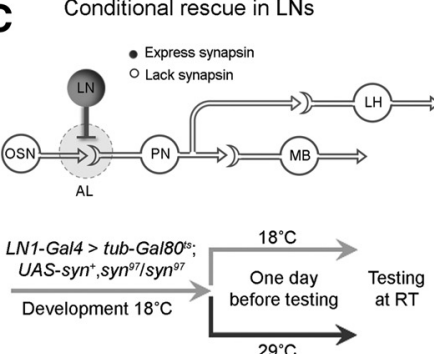

$29^{\circ} \mathrm{C}$

D
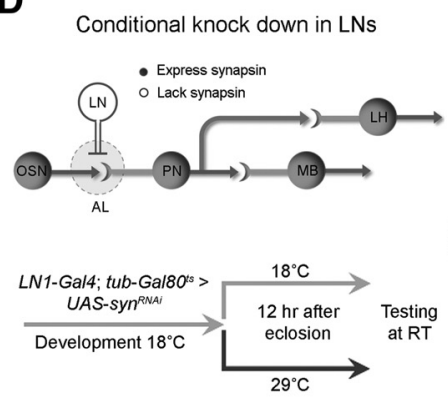
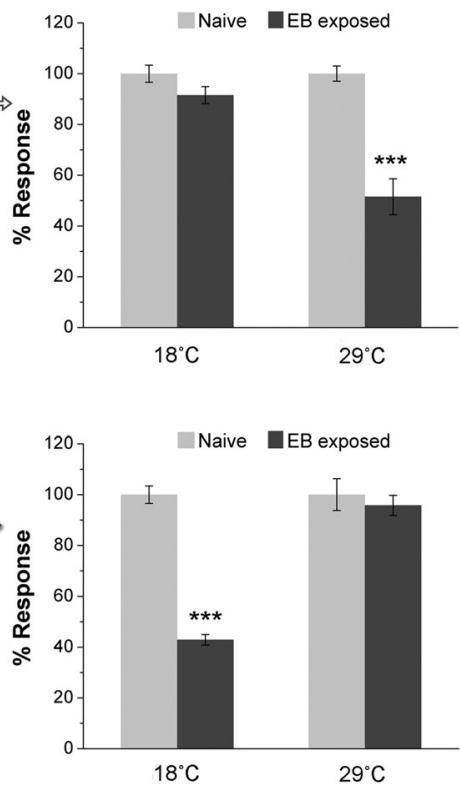

Figure 2. Synapsin function is required in GABAergic LNs for inducing STH. A, Expression of wild-type synapsin transgene in different cell types of olfactory neurons-LNs (LN1-Gal4 $>$

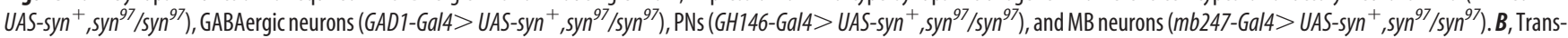
genic expression of synapsin in LN1 or GAD1 subsets of neurons rescue the syn ${ }^{97} \mathrm{STH}$ defect. $\boldsymbol{C}, \boldsymbol{D}$, Expression of synapsin in a different subset of olfactory neurons and temperature-shift protocols are shown in the schematic for conditional rescue and knock down of synapsin using tubGal8O $0^{\text {ts }}$. Filled circles correspond to synapsin expression, whereas an open circle represents lack of synapsin in the

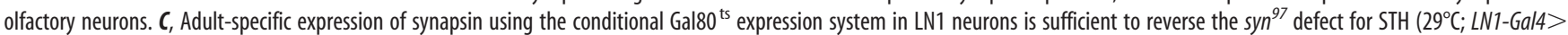
tub-Gal80 ${ }^{t 5}$; UAS-syn ${ }^{+}$, syn $\left.{ }^{97} / \mathrm{syn}^{97}\right)$. Two-way ANOVA yielded a significant difference in the behavioral responses of 18 and $29^{\circ} \mathrm{C}$-treated flies $\left(F_{(1,39)}=19.193, p<0.001\right)$. Post hoc testing $($ Turkey test) showed no difference between naive and EB-exposed flies at $18^{\circ} \mathrm{C}(q=1.893, p=0.189)$ and a significant difference for $29^{\circ} \mathrm{C}$-treated flies $(q=10.655, p<0.001) . \boldsymbol{D}$, Conditional knock down

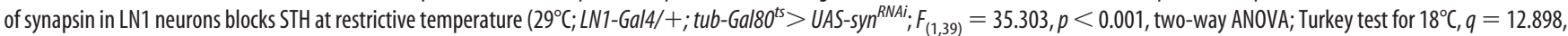
$p<0.001$ and for $29^{\circ} \mathrm{C}$ flies, $q=1.015, p=0.478$ ). Before and after odorant exposure responses to $10^{-3}$ concentration of EB are shown in light gray and dark gray bars, respectively. ${ }^{* * *} p$ value $<$ 0.001 calculated using Student's $t$ test with Bonferroni correction. Error bars indicate mean \pm SEM; $N$ is $9-11$ sets of flies for each bar (Table 1).

leads to enhanced inhibition onto PNs and reduced odor-evoked PN responses after olfactory habituation.

\section{CaMKII phosphorylates synapsin at $\mathrm{S} 6$ and is required for normal STH}

Previous work has shown PKA-dependent recruitment of synaptic reserve pool vesicles possibly mediated by synapsin in Drosophila (Kuromi and Kidokoro, 2000; Fiumara et al., 2004) and revealed that phosphorylation of synapsin by PKA enhances neurotransmitter release in other invertebrates (Fiumara et al., 2004). However, the PKA target consensus RRxS also conforms to the CaMKII target consensus RxxS, which may be particularly relevant since mammalian synapsin is a known substrate for CaMKII (Kao et al., 1999; Hilfiker et al., 2005). Thus the observed requirement of S6 and/or S533 for STH could also indicate a requirement of synapsin phosphorylation by CaMKII. S6 in this context is of particular interest, because it is evolutionarily conserved and it has been shown that the PKA consensus, RRFS, at S6 is edited in most pre-mRNAs by ADAR enzyme to effectively encode RGFS, which although no longer a substrate for bovine PKA in vitro (Diegelmann et al., 2006) still conforms to the CaMKII consensus RxxS (this edited form of the protein rescues odor-reward learning in Drosophila larvae; Michels et al., 2011). We therefore first tested whether Drosophila synapsin could be a substrate for CaMKII and then tested whether CaMKII activity is necessary for behavioral habituation.

To test whether CaMKII activity is necessary to phosphorylate synapsin, we used the elav-Gal4 driver for the targeted expression of a peptide inhibitor for CaMKII (UAS-CaMKII-ala; Griffith et al., 1993) and asked how this affected the phosphorylation state of endogenous synapsin. Compared with parental control flies, synapsin from elav-Gal4> UAS-CaMKII-ala head homogenates showed an increased abundance of an isoform with higher electrophoretic mobility (Fig. 4A, left blot), and a strong reduction of an S6 phosphorylated isoform that is specifically recognized by the $\alpha$-Psyn-S6 antiserum (Fig. 4A, right blot). This suggests that upon expression of the CaMKII inhibitor there is more nonphosphorylated and less phosphorylated synapsin, arguing that CaMKII is involved in the phosphorylation of synapsin S6 in vivo, either directly or indirectly (e.g., via another downstream kinase).

If indeed CaMKII regulation of synapsin is required for its in vivo function in STH, then one would expect that CaMKII function in LNs to be necessary for STH. We tested this prediction.

Using the $t u b-G a l 80^{t_{s}}$ conditional expression system, we expressed the CaMKII inhibitory peptide in the LN1 subset of local interneurons (LN1-Gal4; tub-Gal80 ${ }^{\text {ts }}>$ UAS-CaMKII-ala). When reared, maintained, and tested at a temperature permissive for Gal $80^{\text {ts }}$ function $\left(18^{\circ} \mathrm{C}\right)$, flies displayed normal STH; however, when the $18^{\circ} \mathrm{C}$-reared adult flies were shifted to $29^{\circ} \mathrm{C}$ for $4 \mathrm{~d}$ to induce the CaMKII inhibitor peptide in LN1 neurons, flies showed significantly reduced STH compared with controls (Fig. 4B, Table 1). The conclusion that CaMKII is necessary in LN1 neurons for STH is further supported by the observation that RNAi-mediated knock down of CaMKII in LN1 cells has the same effect as the CaMKII inhibitory peptide expression: LN1-Gal4; tub-Gal80 $0^{t_{5}}>$ UASCaMKII ${ }^{R N A i}$ flies reared at $18^{\circ} \mathrm{C}$ and shifted to $29^{\circ} \mathrm{C}$ for $4 \mathrm{~d}$, showed no detectable STH (Fig. 4C, Table 1). Thus, CaMKII 

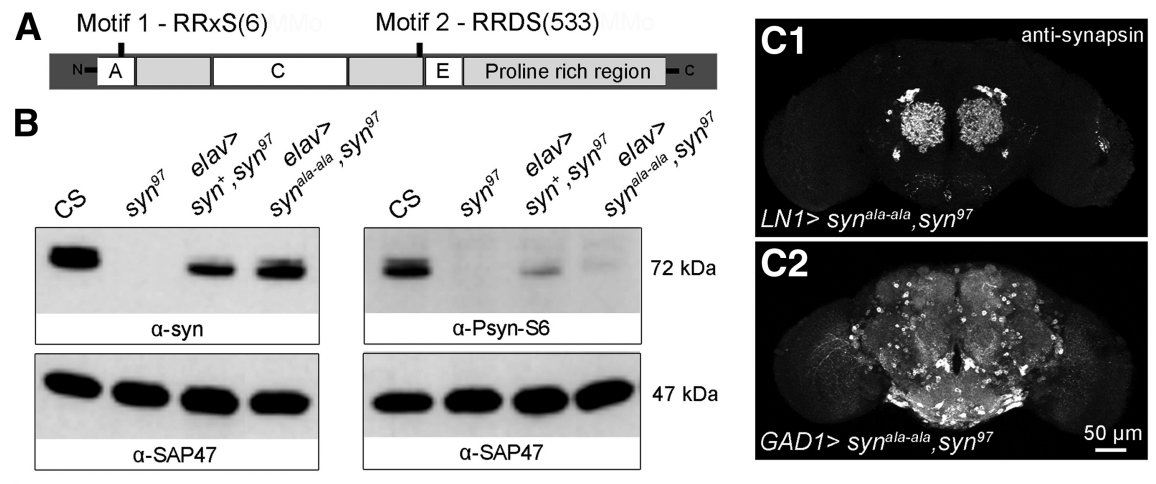

\section{D}

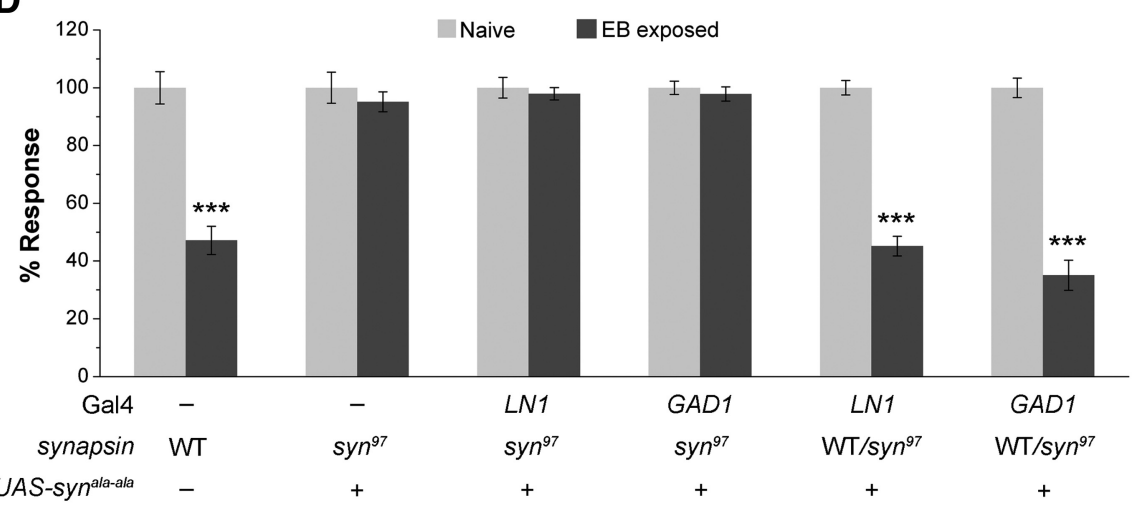

Figure 3. Synapsin phosphorylation sites are essential for STH formation. A, Schematic of synapsin protein with phosphorylation sites at $S 6$ and $S 533$ positions targeted for mutation. In the UAS-syn ${ }^{\text {ala-ala }}$ construct both serines are replaced by alanines ( $S 6 \mathrm{~A}$, S533A). Domains A, C, and E are conserved in vertebrate synapsins. B, Validation of UAS-syn ${ }^{\text {ala-ala }}$ transgenic flies using S6-specific phospho-antibody ( $\alpha$-Psyn-S6). elav-Gal4 $>$ UAS-syn ala-ala syn $^{97} /$ syn $^{97}$ flies (fourth lane in each blot) express a protein recognized by $\alpha$-synapsin antibody (3C11), but not by $\alpha$-Psyn-S6. C, $\alpha$-Synapsin immunoreactivity in LN1 and GAD1 neurons with UAS-syn ${ }^{\text {ala-ala }}$ transgenic expression in syn ${ }^{97}$ mutant background. D, Expression of synapsin with mutated motifs 1 and 2 in LN1 (LN1Gal4> UAS-syn ala-ala, syn $^{97} /$ syn $^{97}$ ) or GABAergic neurons (GAD1-Gal4 $>$ UAS-syn ${ }^{\text {allala }}$, syn $n^{97} /$ syn $^{97}$ ) fails to rescue the syn ${ }^{97}$ defect for STH. Before and after odorant exposure are represented as light gray and dark gray bars, respectively, along with mean \pm SEM, $N$ for each bar is 8-11 sets (Table 1). ${ }^{* * *} p<0.001$ (Student'st test with Bonferroni correction). WT, wild-type.

has a key role in olfactory habituation as well as for synapsin phosphorylation, which is necessary for STH.

\section{LTH is synapsin independent although it depends on CaMKII and cAMP signaling}

Additional experiments indicated that inhibition of CaMKII in LNs also blocked LTH (Fig. 4D, Table 2). Given the need for CaMKII activity for LTH, we further tested whether synapsin function is also essential for LTH, which has previously been associated with gene expression and odorant-selective glomerular growth (Devaud et al., 2001; Sachse et al., 2007; Das et al., 2011; McCann et al., 2011). Remarkably, syn ${ }^{97}$ flies, which show no detectable STH, displayed normal reduction in the behavioral response after $4 \mathrm{~d}$ of EB exposure. Indeed LTH occurred at levels comparable to that of wild-type flies (Fig. $5 A$, Table 2).

Moreover, LTH-induced selective glomerular growth occurred in $s y n^{97}$ mutants just as observed in control wild-type flies (Das et al., 2011). In response to EB exposure, the EB-responsive glomeruli DM2 and DM5 increased in volume after $4 \mathrm{~d}$ of EB exposure, while the $\mathrm{CO}_{2}$-responsive $\mathrm{V}$ glomerulus remain unchanged (Fig. $5 B$ ). These observations lead to two major conclusions. First, synapsin function, though essential in GABAergic LNs for short-term plasticity, is dispensable for long-term behavioral and structural plasticity. Second, for olfactory habituation, long-term memory can form in the absence of behaviorally measured shortterm memory.

\section{Discussion}

The defined neuronal network that mediates olfactory STH and LTH on Drosophila makes it an attractive system for attempts to understand circuit mechanisms of synaptic plasticity that underlie these forms of non-associative memory in vivo (Sachse et al., 2007; Larkin et al., 2010; Das et al., 2011; Sudhakaran et al., 2012). Observations presented here indicate the following: (1) that synapsindependent facilitation of GABA release from LNs underlies olfactory STH, (2) that this facilitation requires CaMKII kinase function in LNs, and (3) that LTH can form in the absence of STH. We discuss the evidence for and implications of these conclusions.

\section{Synapsin phosphorylation-mediated GABA facilitation in LNs is necessary for STH}

Previous studies have established the important roles for vertebrate and invertebrate synapsins in short-term synaptic plasticity (Rosahl et al., 1993, 1995). Our conclusion that increased GABA release underlies olfactory STH is built on previous studies that have established the role of synapsin in synaptic vesicle mobilization and presynaptic facilitation (Greengard et al., 1993; Pieribone et al., 1995; Hilfiker et al., 1999). Several in vivo and in vitro studies have provided evidence that synapsin phosphorylation and dephosphorylation regulate the effective size of different vesicle pools and thereby control neurotransmitter release. In the mollusks Aplysia californica and Helix pomatia/aspersa, the phosphorylation and redistribution of synapsin induced by the PKA or MAPK/Erk-pathways mediates short-term facilitation of transmitter release (Byrne and Kandel, 1996; Angers et al., 2002; Giachello et al., 2010). In Drosophila larval neuromuscular junctions, post-tetanic potentiation of transmitter release requires synapsin function and is accompanied by mobilization of a reserve pool of synaptic vesicles (Kuromi and Kidokoro, 2000, 2002; Akbergenova and Bykhovskaia, 2007). And in the mouse CNS, enhanced ERK signaling in the inhibitory neurons results in increased levels of synapsin-1 phosphorylation and enhanced GABA release from hippocampal interneurons (Cui et al., 2008).

In context of these prior studies of synapsin, our observation that synapsin and its phosphorylation are necessary in GABAergic local interneurons for STH indicates that the facilitation of GABA release from LNs attenuates excitatory signals in the AL and thereby results in the reduced behavioral response, characteristic of habituation. The molecular reversibility of phosphorylation could potentially account for the spontaneous recovery of the olfactory response after STH. These in vivo observations on synapsin function constitute a substantial advance as they show that synapsin-mediated plasticity, usually observed in response 
to experimentally enforced electrophysiological stimulations, can underlie behavioral learning and memory induced by sensory experience. In addition, by placing these changes in an identified subpopulation of local inhibitory interneurons in the AL, they implicate presynaptic plasticity of LNs as a mechanism necessary for habituation and thereby substantially clarify a neural circuit mechanism for this form of nonassociative memory.

\section{CaMKII regulates synapsin phosphorylation and STH}

A significant question is how synapsin phosphorylation is regulated in vivo for synaptic plasticity and how this contributes to altered circuit function that underlies behavioral learning. This has been difficult to address for two reasons: first, due to the complexity and potential promiscuity of kinase signaling pathways, and second, this requires not only the identification of neurons that show synapsin-dependent plasticity, but also concurrent understanding of the circuit functions of these neurons and their postsynaptic target(s) in vivo. The latter has been a particular challenge in neural networks for behavioral memory. For instance, although synapsin- and S6/S533dependent odor-reward memory trace localized to the MBs (Michels et al., 2011), the downstream targets of the MB to mediate learned behavior are only beginning to be unraveled. This makes it difficult to comprehensively interpret the complex role of synapsin in associative memory illustrated by the finding that $3 \mathrm{~min}$ memory and anesthesia-sensitive $2 \mathrm{~h}$ memory require synapsin, whereas $5 \mathrm{~h}$ memory and anesthesia-resistant $2 \mathrm{~h}$ memory do not (Knapek et al., 2010). In the Drosophila neural circuit that underlies olfactory habituation, we present evidence that is most parsimoniously explained by a model in which CaMKII regulates synapsin phosphorylation in GABAergic LNs of the AL, neurons that are known to inhibit projection neurons that transmit olfactory input to higher brain centers.

Our in vivo CaMKII studies not only show the requirement of its function in olfactory habituation, but also demonstrate that the predominant form of synapsin, which arises from pre-mRNA editing (Diegelmann et al., 2006), is a potent substrate for CaMKII. Thus, expression of an inhibitory CaMKII peptide in neurons not only reduces (yet does not abolish) the S6phosphorylated form of synapsin detected using S6 phosphospecific antibody, it also blocks olfactory habituation, thereby providing experimental evidence for presynaptic function of CaMKII. These findings provide in vivo support for the original model of Greengard et al. (1993) and Menegon et al. (2002) that proposed the primacy of CaMKII regulation of synapsin function; however, the structural basis for this regulation may be slightly different as invertebrate synapsins lack the D domain and 2 for $N$.
B Conditional CaMKII inhibition - STH

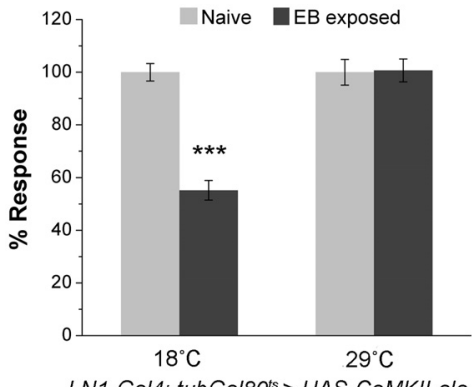

LN1-Gal4; tubGal80ts > UAS-CaMKII-ala

D Conditional CaMKII inhibition - LTH

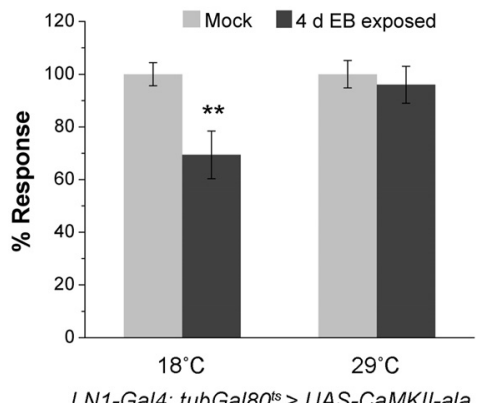

LN1-Gal4; tubGal80ts > UAS-CaMKII-ala

Figure 4. CaMKII-dependent phosphorylation is necessary for STH. A, Western blot showing the effect of pan-neuronal overexpression of CaMKII-inhibitory peptide ala on synapsin phosphorylation. Inhibition of CaMKII activity causes a significantly $18^{\circ} \mathrm{C}$ flies, $q=10.066, p<0.001$ and for $29^{\circ} \mathrm{C}$-treated flies, $\left.q=0.167, p=0.907\right)$ and $(\boldsymbol{C})$ knock down of CaMKII (LN1-Gal4 (UAS-CaMKIIINAi) $\left(F_{(1,35)}=80.498, p<0.001\right.$, two-way ANOVA; Turkey test for $18^{\circ} \mathrm{C}$ flies, $q=17.442, p<0.001$ (LN1-Gal4; tub-Gal80 $>$ UAS-CaMKIl-ala), on LTH $\left(F_{(1,28)}=3.402, p=0.077\right.$, two-way ANOVA; Turke) bars indicate \pm SEM. ${ }^{* * *} p<0.001$ and ${ }^{* *} p<0.01$ equal to 0.001 (Student's $t$ test with Bonferroni correction). Refer to Tables 1

found on mammalian homologs that appear to be the major targets of CaMKII-dependent synapsin phosphorylation.

Our conclusions on the role of CaMKII must be qualified in two ways. First, though we show tight correlations between CaMKII phosphorylation of synapsin and the protein's function in STH, our data fall short of establishing causality. Second, we have not been able to directly demonstrate that odorant exposure that induces STH results in CaMKII-dependent synapsin phosphorylation in LNs. Attempts to address the latter issue failed because of technical difficulties in using phospho-specific antibodies for in vivo immunohistochemistry. Finally, although we propose that CaMKII phosphorylation is necessary for synapsin function during STH, it remains possible that other additional kinases, e.g., PKA and CaMKI (Knapek et al., 2010; Diegelmann et al., 2013), also contribute to synapsin regulation in vivo required for STH.

\section{Long-term memory without short-term memory}

Several studies have discriminated between mechanisms of shortterm and long-term memory (STM and LTM) formation. Most have focused on the distinctive requirement for protein synthesis in LTM and have not established whether STM is a necessary step 
Table 2. Showing the RI values for mock and odor-exposed flies along with number sets, $t$ values, and $p$ values for all the experimental genotypes

\begin{tabular}{|c|c|c|c|c|c|c|c|}
\hline \multirow[b]{2}{*}{ Figure } & \multirow[b]{2}{*}{ Genotype (LTH experiments) } & \multicolumn{3}{|c|}{ Negative RI for EB LTH } & \multicolumn{3}{|c|}{ Negative RI for $\mathrm{CO}_{2} \mathrm{LTH}$} \\
\hline & & Mock exposed & EB exposed & $\begin{array}{l}t_{(\mathrm{df})}=t \text { value, } \\
p=p \text { value }\end{array}$ & Mock exposed & $\mathrm{CO}_{2}$ exposed & $\begin{array}{l}t_{(\mathrm{df})}=t \text { value, } \\
p=p \text { value }\end{array}$ \\
\hline \multirow[t]{2}{*}{$4 \mathrm{D}$} & $\begin{array}{l}\text { LN1-Gal4/UAS-CaMKII-ala; tub-Gal80's/ } \\
\quad+-18^{\circ} \mathrm{C}\end{array}$ & $0.61 \pm 0.03(8)$ & $0.42 \pm 0.06(8)$ & $t_{(14)}=-3.03, p<0.01$ & - & - & - \\
\hline & $\begin{array}{l}\text { LN1-Gal4/UAS-CaMKII-ala; tub-Galso } 0^{\text {ts }} \\
\quad+-29^{\circ} \mathrm{C}\end{array}$ & $0.63 \pm 0.03(7)$ & $0.62 \pm 0.05(6)$ & $t_{(11)}=-0.43, p=0.68$ & - & - & - \\
\hline $5 \mathrm{~A}$ & $\begin{array}{l}\text { CS } \\
\operatorname{syn}^{97}\end{array}$ & $\begin{array}{l}0.67 \pm 0.01(10) \\
0.71 \pm 0.02(9)\end{array}$ & $\begin{array}{l}0.30 \pm 0.03(9) \\
0.33 \pm 0.01(10)\end{array}$ & $\begin{array}{l}t_{(17)}=-12.19, p<0.001 \\
t_{(17)}=-19.16, p<0.001\end{array}$ & $\begin{array}{l}0.53 \pm 0.01(9) \\
0.58 \pm 0.02(10)\end{array}$ & $\begin{array}{l}0.24 \pm 0.01(9) \\
0.25 \pm 0.02(9)\end{array}$ & $\begin{array}{l}t_{(16)}=-14.74, p<0.001 \\
t_{(17)}=-14.78, p<0.001\end{array}$ \\
\hline
\end{tabular}

A

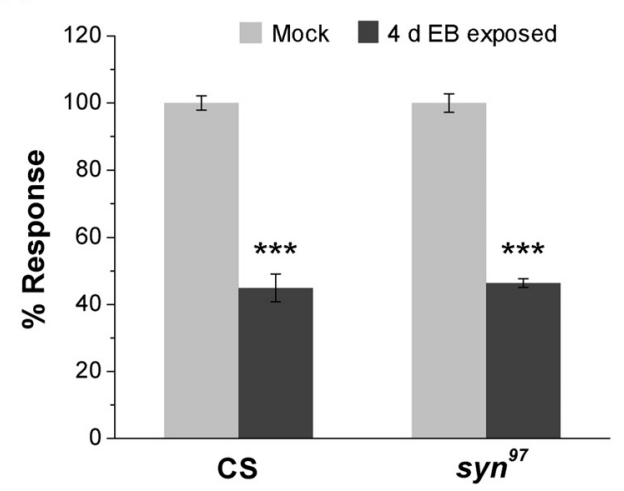

B

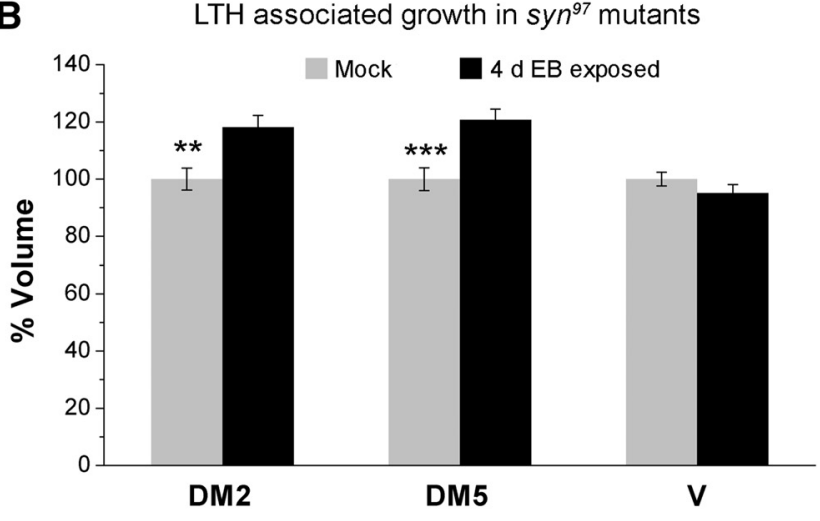

Figure 5. LTH is a synapsin independent mechanism. $A$, Histogram showing the LTH responses for CS and $\operatorname{syn} n^{97}$ flies $\left(F_{(1,37)}=0.104, p=0.749\right.$, two-way ANOVA; Turkey test for CS flies, $q=$ $20.385, p<0.001$ and for $\operatorname{syn}^{97}$ flies, $\left.q=21.031, p<0.001\right)$. Light gray and dark gray bars correspond to behavioral responses to a $10^{-3}$ dilution of $E B$, after $4 \mathrm{~d}$ of exposure to paraffin oil and EB, respectively. $N$ for each bar is $9-10$ sets (Table 2). $\boldsymbol{B}$, Change in the volume of DM2, DM5, and V glomerulus, shown in light gray and black bars, respectively, for mock- and EB-exposed syn ${ }^{97}$ flies. Raw values for glomerular volumes $\left(\mu \mathrm{m}^{3} \pm \mathrm{SEM}\right)$ of mock-and EB-exposed flies with number of measured glomeruli in the parentheses and statistical results $\left[t_{\text {(df) }}=t\right.$ value, $p=p$ value]: for DM2 glomeruli, $2680 \pm 103(16)$ and $3168 \pm 110(20), t_{(34)}=3.16, p=0.003$; for DM5 glomeruli, $1086 \pm 43$ (16) and $1311 \pm 40(18), t_{(32)}=3.81, p<0.001$ and for V glomeruli, $4649 \pm 112$ (16) and $4420 \pm 140(20)$ with a $t_{(34)}=-1.23, p=0.227$. Two-way ANOVA yielded a significant difference between mock- and EB-exposed flies $\left(F_{(2,105)}=6.284, p=0.003\right)$. Error bars indicate mean \pm SEM. ${ }^{* * *} p<0.001$ and ${ }^{* *} p<0.01$ equal to 0.001 calculated using Student's $t$ test with Bonferroni correction.

in the formation of LTM or whether STM and LTM arise via distinctive, if partially overlapping molecular pathways (Kandel, 2001; Bailey et al., 2004). However, a few reports describe experimental perturbations that greatly reduce STM, without altering LTM.

In cultured sensorimotor synapses, which provide a surrogate model for behavioral sensitization in Aplysia, Emptage and Carew (1993) showed that synaptic application of a selective 5-HT receptor antagonist blocked short-term facilitation while leaving long-term facilitation unaffected. In contrast, somatic application of the same antagonist selectively blocked long-term facilitation. This showed that long-term synaptic plasticity, though triggered by similar inputs (5-HT in this case), can progress through a pathway that does not require short-term plasticity (Emptage and Carew, 1993).

In mammalian systems, Izquierdo et al. showed that a variety of pharmacological infusions into the hippocampal CA1 region or in entorhinal/ parietal cortex inhibited STM without affecting LTM of a shock avoidance memory task (Izquierdo et al., 1998, 1999, 2002; Vianna et al., 2000; Sanderson et al., 2009). In Drosophila, different isoforms of A-kinase anchor protein (AKAP) interacts with cAMP-PKA and play a distinct role in the formation of STM and LTM (Lu et al., 2007; Zhao et al., 2013). While these studies indicate that LTM is not built on STM, they do not rule out the possibility that they share an early common synaptic mechanism, but differ in subsequent mechanisms of consolidation, which occur in anatomically distinct brain regions.

Our current observations on the absolute requirement for synapsin in STH but not LTH extend a model in which LTM can

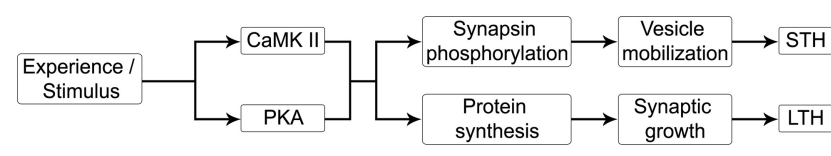

Figure 6. Schematic showing the synaptic mechanisms proposed to underlie olfactory habituation in Drosophila.

be encoded without transition through STM, particularly because STH and LTH involve different timescales of plasticity in the very same olfactory neurons. In the simple learning circuit for STH and LTH, we interpret our observations in a biochemical model illustrated in Figure 6. While both STH and LTH occur through potentiation of iLN-PN synapses, we propose that while the signaling mechanisms for short- and long-term synaptic plasticity diverge before the stage of synapsin phosphorylation in GABAergic local interneurons. Thus, odorant exposure results in the activation of key signaling molecules such as PKA and CaMKII in LNs required for both forms of olfactory habituation. However, the kinases affect STH through synapsin phosphorylation, which results in a rapid but transient increase in evoked GABA release. Meanwhile, the same signaling molecules also participate in the activation of translational and/or transcriptional control machinery, which act, on a slower timescale, to cause the formation of additional GABAergic synapses that persist stably for much longer periods of time.

The unusual behavioral state, in which an animal is unable to form an STM but capable of longer term memory may have some clinical significance. Recently, a comprehensive mouse model for 
Down syndrome, which is trisomic for $\sim 92 \%$ of the human chromosome 21, was shown to have defective STM of novel object recognition, while still showing normal LTM in this task, which is conceptually similar to behavioral habituation (Morice et al., 2008). Thus, we suggest that further studies may eventually identify several other molecules which, like synapsin, are selectively necessary for short-term but not for long-term memory.

\section{References}

Akbergenova Y, Bykhovskaia M (2007) Synapsin maintains the reserve vesicle pool and spatial segregation of the recycling pool in Drosophila presynaptic boutons. Brain Res 1178:52-64. CrossRef Medline

Angers A, Fioravante D, Chin J, Cleary LJ, Bean AJ, Byrne JH (2002) Serotonin stimulates phosphorylation of Aplysia synapsin and alters its subcellular distribution in sensory neurons. J Neurosci 22:5412-5422. Medline

Bailey CH, Kandel ER, Si K (2004) The persistence of long-term memory: a molecular approach to self-sustaining changes in learning-induced synaptic growth. Neuron 44:49-57. CrossRef Medline

Byrne JH, Kandel ER (1996) Presynaptic facilitation revisited: state and time dependence. J Neurosci 16:425-435. Medline

Cesca F, Baldelli P, Valtorta F, Benfenati F (2010) The synapsins: key actors of synapse function and plasticity. Prog Neurobiol 91:313-348. CrossRef Medline

Chou YH, Spletter ML, Yaksi E, Leong JC, Wilson RI, Luo L (2010) Diversity and wiring variability of olfactory local interneurons in the Drosophila antennal lobe. Nat Neurosci 13:439-449. CrossRef Medline

Cui Y, Costa RM, Murphy GG, Elgersma Y, Zhu Y, Gutmann DH, Parada LF, Mody I, Silva AJ (2008) Neurofibromin regulation of ERK signaling modulates GABA release and learning. Cell 135:549-560. CrossRef Medline

Das S, Sadanandappa MK, Dervan A, Larkin A, Lee JA, Sudhakaran IP, Priya R, Heidari R, Holohan EE, Pimentel A, Gandhi A, Ito K, Sanyal S, Wang JW, Rodrigues V, Ramaswami M (2011) Plasticity of local GABAergic interneurons drives olfactory habituation. Proc Natl Acad Sci U S A 108: E646-654. CrossRef Medline

Devaud JM, Acebes A, Ferrús A (2001) Odor exposure causes central adaptation and morphological changes in selected olfactory glomeruli in Drosophila. J Neurosci 21:6274-6282. Medline

Diegelmann S, Nieratschker V, Werner U, Hoppe J, Zars T, Buchner E (2006) The conserved protein kinase-A target motif in synapsin of Drosophila is effectively modified by pre-mRNA editing. BMC Neurosci 7:76. CrossRef Medline

Diegelmann S, Klagges B, Michels B, Schleyer M, Gerber B (2013) Maggot learning and Synapsin function. J Exp Biol 216:939-951. CrossRef Medline

Emptage NJ, Carew TJ (1993) Long-term synaptic facilitation in the absence of short-term facilitation in Aplysia neurons. Science 262:253-256. CrossRef Medline

Fiumara F, Giovedì S, Menegon A, Milanese C, Merlo D, Montarolo PG, Valtorta F, Benfenati F, Ghirardi M (2004) Phosphorylation by cAMPdependent protein kinase is essential for synapsin-induced enhancement of neurotransmitter release in invertebrate neurons. J Cell Sci 117:51455154. CrossRef Medline

Giachello CN, Fiumara F, Giacomini C, Corradi A, Milanese C, Ghirardi M, Benfenati F, Montarolo PG (2010) MAPK/Erk-dependent phosphorylation of synapsin mediates formation of functional synapses and shortterm homosynaptic plasticity. J Cell Sci 123:881-893. CrossRef Medline

Giachello CN, Montarolo PG, Ghirardi M (2012) Synaptic functions of invertebrate varicosities: what molecular mechanisms lie beneath. Neural Plast 2012:670821. Medline

Godenschwege TA, Reisch D, Diegelmann S, Eberle K, Funk N, Heisenberg M, Hoppe V, Hoppe J, Klagges BR, Martin JR, Nikitina EA, Putz G, Reifegerste R, Reisch N, Rister J, Schaupp M, Scholz H, Schwärzel M, Werner U, Zars TD, et al. (2004) Flies lacking all synapsins are unexpectedly healthy but are impaired in complex behaviour. Eur J Neurosci 20: 611-622. CrossRef Medline

Greengard P, Valtorta F, Czernik AJ, Benfenati F (1993) Synaptic vesicle phosphoproteins and regulation of synaptic function. Science 259:780785. CrossRef Medline

Griffith LC, Verselis LM, Aitken KM, Kyriacou CP, Danho W, Greenspan RJ
(1993) Inhibition of calcium/calmodulin-dependent protein kinase in Drosophila disrupts behavioral plasticity. Neuron 10:501-509. CrossRef Medline

Halder P, Chen YC, Brauckhoff J, Hofbauer A, Dabauvalle MC, Lewandrowski U, Winkler C, Sickmann A, Buchner E (2011) Identification of Eps 15 as antigen recognized by the monoclonal antibodies aa2 and ab52 of the Wuerzburg Hybridoma Library against Drosophila brain. PLoS One 6:e29352. CrossRef Medline

Hilfiker S, Pieribone VA, Czernik AJ, Kao HT, Augustine GJ, Greengard P (1999) Synapsins as regulators of neurotransmitter release. Philos Trans R Soc Lond B Biol Sci 354:269-279. CrossRef Medline

Hilfiker S, Benfenati F, Doussau F, Nairn AC, Czernik AJ, Augustine GJ, Greengard P (2005) Structural domains involved in the regulation of transmitter release by synapsins. J Neurosci 25:2658-2669. CrossRef Medline

Hofbauer A, Ebel T, Waltenspiel B, Oswald P, Chen YC, Halder P, Biskup S, Lewandrowski U, Winkler C, Sickmann A, Buchner S, Buchner E (2009) The Wuerzburg hybridoma library against Drosophila brain. J Neurogenet 23:78-91. CrossRef Medline

Hosaka M, Südhof TC (1998a) Synapsins I and II are ATP-binding proteins with differential Ca2 + regulation. J Biol Chem 273:1425-1429. CrossRef Medline

Hosaka M, Südhof TC (1998b) Synapsin III, a novel synapsin with an unusual regulation by $\mathrm{Ca} 2+$. J Biol Chem 273:13371-13374. CrossRef Medline

Hosaka M, Hammer RE, Südhof TC (1999) A phospho-switch controls the dynamic association of synapsins with synaptic vesicles. Neuron 24:377387. CrossRef Medline

Izquierdo I, Barros DM, Mello e Souza T, de Souza MM, Izquierdo LA, Medina JH (1998) Mechanisms for memory types differ. Nature 393: 635-636. CrossRef Medline

Izquierdo I, Medina JH, Vianna MR, Izquierdo LA, Barros DM (1999) Separate mechanisms for short- and long-term memory. Behav Brain Res 103:1-11. CrossRef Medline

Izquierdo LA, Barros DM, Vianna MR, Coitinho A, deDavid e Silva T, Choi H, Moletta B, Medina JH, Izquierdo I (2002) Molecular pharmacological dissection of short- and long-term memory. Cell Mol Neurobiol 22: 269-287. CrossRef Medline

Kandel ER (2001) The molecular biology of memory storage: a dialogue between genes and synapses. Science 294:1030-1038. CrossRef Medline

Kao HT, Porton B, Hilfiker S, Stefani G, Pieribone VA, DeSalle R, Greengard P (1999) Molecular evolution of the synapsin gene family. J Exp Zool 285:360-377. CrossRef Medline

Klagges BR, Heimbeck G, Godenschwege TA, Hofbauer A, Pflugfelder GO, Reifegerste R, Reisch D, Schaupp M, Buchner S, Buchner E (1996) Invertebrate synapsins: a single gene codes for several isoforms in Drosophila. J Neurosci 16:3154-3165. Medline

Knapek S, Gerber B, Tanimoto H (2010) Synapsin is selectively required for anesthesia-sensitive memory. Learn Mem 17:76-79. CrossRef Medline

Kuromi H, Kidokoro Y (2000) Tetanic stimulation recruits vesicles from reserve pool via a cAMP-mediated process in Drosophila synapses. Neuron 27:133-143. CrossRef Medline

Kuromi H, Kidokoro Y (2002) Selective replenishment of two vesicle pools depends on the source of $\mathrm{Ca} 2+$ at the Drosophila synapse. Neuron 35 : 333-343. CrossRef Medline

Larkin A, Karak S, Priya R, Das A, Ayyub C, Ito K, Rodrigues V, Ramaswami M (2010) Central synaptic mechanisms underlie short-term olfactory habituation in Drosophila larvae. Learn Mem 17:645-653. CrossRef Medline

Li L, Chin LS, Shupliakov O, Brodin L, Sihra TS, Hvalby O, Jensen V, Zheng D, McNamara JO, Greengard P (1995) Impairment of synaptic vesicle clustering and of synaptic transmission, and increased seizure propensity, in synapsin I-deficient mice. Proc Natl Acad Sci U S A 92:9235-9239. CrossRef Medline

Llinás R, McGuinness TL, Leonard CS, Sugimori M, Greengard P (1985) Intraterminal injection of synapsin I or calcium/calmodulin-dependent protein kinase II alters neurotransmitter release at the squid giant synapse. Proc Natl Acad Sci U S A 82:3035-3039. CrossRef Medline

Löhr R, Godenschwege T, Buchner E, Prokop A (2002) Compartmentalization of central neurons in Drosophila: a new strategy of mosaic analysis reveals localization of presynaptic sites to specific segments of neurites. J Neurosci 22:10357-10367. Medline 
Lu Y, Lu YS, Shuai Y, Feng C, Tully T, Xie Z, Zhong Y, Zhou HM (2007) The AKAP Yu is required for olfactory long-term memory formation in Drosophila. Proc Natl Acad Sci U S A 104:13792-13797. CrossRef Medline

McCann C, Holohan EE, Das S, Dervan A, Larkin A, Lee JA, Rodrigues V, Parker R, Ramaswami M (2011) The Ataxin-2 protein is required for microRNA function and synapse-specific long-term olfactory habituation. Proc Natl Acad Sci U S A 108:E655-E662. CrossRef Medline

Menegon A, Verderio C, Leoni C, Benfenati F, Czernik AJ, Greengard P, Matteoli M, Valtorta F (2002) Spatial and temporal regulation of Ca2+/ calmodulin-dependent protein kinase II activity in developing neurons. J Neurosci 22:7016-7026. Medline

Michels B, Diegelmann S, Tanimoto H, Schwenkert I, Buchner E, Gerber B (2005) A role for Synapsin in associative learning: the Drosophila larva as a study case. Learn Mem 12:224-231. CrossRef Medline

Michels B, Chen YC, Saumweber T, Mishra D, Tanimoto H, Schmid B, Engmann O, Gerber B (2011) Cellular site and molecular mode of synapsin action in associative learning. Learn Mem 18:332-344. CrossRef Medline

Morice E, Andreae LC, Cooke SF, Vanes L, Fisher EM, Tybulewicz VL, Bliss TV (2008) Preservation of long-term memory and synaptic plasticity despite short-term impairments in the Tc1 mouse model of Down syndrome. Learn Mem 15:492-500. CrossRef Medline

Nuwal T, Heo S, Lubec G, Buchner E (2011) Mass spectrometric analysis of synapsins in Drosophila melanogaster and identification of novel phosphorylation sites. J Proteome Res 10:541-550. CrossRef Medline

Pieribone VA, Shupliakov O, Brodin L, Hilfiker-Rothenfluh S, Czernik AJ, Greengard P (1995) Distinct pools of synaptic vesicles in neurotransmitter release. Nature 375:493-497. CrossRef Medline

Rosahl TW, Geppert M, Spillane D, Herz J, Hammer RE, Malenka RC, Südhof
TC (1993) Short-term synaptic plasticity is altered in mice lacking synapsin I. Cell 75:661-670. CrossRef Medline

Rosahl TW, Spillane D, Missler M, Herz J, Selig DK, Wolff JR, Hammer RE, Malenka RC, Südhof TC (1995) Essential functions of synapsins I and II in synaptic vesicle regulation. Nature 375:488-493. CrossRef Medline

Sachse S, Rueckert E, Keller A, Okada R, Tanaka NK, Ito K, Vosshall LB (2007) Activity-dependent plasticity in an olfactory circuit. Neuron 56 : 838-850. CrossRef Medline

Sanderson DJ, Good MA, Skelton K, Sprengel R, Seeburg PH, Rawlins JN, Bannerman DM (2009) Enhanced long-term and impaired short-term spatial memory in GluA1 AMPA receptor subunit knockout mice: evidence for a dual-process memory model. Learn Mem 16:379-386. CrossRef Medline

Sudhakaran IP, Holohan EE, Osman S, Rodrigues V, Vijayraghavan K, Ramaswami M (2012) Plasticity of recurrent inhibition in the Drosophila antennal lobe. J Neurosci 32:7225-7231. CrossRef Medline

Südhof TC, Czernik AJ, Kao HT, Takei K, Johnston PA, Horiuchi A, Kanazir SD, Wagner MA, Perin MS, De Camilli P, et al. (1989) Synapsins: mosaics of shared and individual domains in a family of synaptic vesicle phosphoproteins. Science 245:1474-1480. CrossRef Medline

Vianna MR, Izquierdo LA, Barros DM, Walz R, Medina JH, Izquierdo I (2000) Short- and long-term memory: differential involvement of neurotransmitter systems and signal transduction cascades. An Acad Bras Cienc 72:353-364. CrossRef Medline

Vosshall LB, Stocker RF (2007) Molecular architecture of smell and taste in Drosophila. Annu Rev Neurosci 30:505-533. CrossRef Medline

Zhao J, Lu Y, Zhao X, Yao X, Shuai Y, Huang C, Wang L, Jeong SH, Zhong Y (2013) Dissociation of rugose-dependent short-term memory component from memory consolidation in Drosophila. Genes Brain Behav 12: 626-632. CrossRef Medline 